(2) OPEN ACCESS

\title{
Pregnancy outcome in thoracic aortic disease data from the Registry Of Pregnancy And Cardiac disease
}

\author{
Laurence Campens (i) , ${ }^{1}$ Lucia Baris, ${ }^{2}$ Nandita S. Scott, ${ }^{3}$ Craig S Broberg, ${ }^{4}$ \\ Antione Bondue, ${ }^{5}$ Guillaume Jondeau, ${ }^{6}$ Jasmine Grewal (i) , Mark R Johnson, ${ }^{8}$ \\ Roger Hall, ${ }^{9}$ Julie De Backer 다, ${ }^{1,10}$ Jolien W Roos-Hesselink $\left(\mathbb{0},{ }^{2}\right.$ On behalf of the \\ ROPAC investigators group
}

\begin{abstract}
- Additional material is published online only. To view please visit the journal online (http://dx.doi.org/10.1136/ heartjnl-2020-318183).

For numbered affiliations see end of article.
\end{abstract}

\section{Correspondence to} Dr Jolien W Roos-Hesselink, Cardiology Department, Erasmus Medical Center, 3015 GD Rotterdam, Netherlands; j.roos@erasmusmc.nl

LC and LB are joint first authors. JDB and JWR-H are joint last authors.

Received 4 September 2020 Revised 15 December 2020 Accepted 15 December 2020 Published Online First 19 January 2021

\begin{abstract}
Background Cardiovascular disease is the leading cause of death during pregnancy with thoracic aortic dissection being one of the main causes. Thoracic aortic disease is commonly related to hereditary disorders and congenital heart malformations such as bicuspid aortic valve (BAV). Pregnancy is considered a high risk period in women with underlying aortopathy.

Methods The ESC EORP Registry Of Pregnancy And Cardiac disease (ROPAC) is a prospective global registry that enrolled 5739 women with pre-existing cardiac disease. With this analysis, we aim to study the maternal and fetal outcome of pregnancy in women with thoracic aortic disease.

Results Thoracic aortic disease was reported in 189 women (3.3\%). Half of them were patients with Marfan syndrome (MFS), 26\% had a BAV, 8\% Turner syndrome, $2 \%$ vascular Ehlers-Danlos syndrome and $11 \%$ had no underlying genetic defect or associated congenital heart defect. Aortic dilatation was reported in 58\% of patients and $6 \%$ had a history of aortic dissection. Four patients, of whom three were patients with MFS, had an acute aortic dissection (three type $A$ and one type $B$ aortic dissection) without maternal or fetal mortality. No complications occurred in women with a history of aortic dissection. There was no significant difference in median fetal birth weight if treated with a beta-blocker or not (2960 g (2358-3390 g) vs 3270 g (2750-3570 g), $p$ value 0.25 )
\end{abstract}

Conclusion This ancillary analysis provides the largest prospective data review on pregnancy risk for patients with thoracic aortic disease. Overall pregnancy outcomes in women with thoracic aortic disease followed according to current guidelines are good.

\section{INTRODUCTION}

Aortic complications during pregnancy are particularly a concern in women with underlying connective tissue diseases such as Marfan syndrome (MFS), vascular Ehlers-Danlos syndrome (vEDS), Loeys-Dietz syndrome (LDS) and SMAD3 aortopathy, but also women with Turner syndrome (TS) and congenital heart malformations like bicuspid aortic valve (BAV) may be more prone. ${ }^{12}$

Data obtained from the GenTAC registry on MFS show a significantly higher aortic dissection rate of 5.4 per 100 person-years during pregnancy and the postpartum period compared with a non-pregnancy dissection rate of 0.6 per 100 patient-years. ${ }^{3}$ However, data on the immediate and long-term effects of pregnancy on aortic outcome are not uniform due to publication and ascertainment biases, reports on small sample sizes and inclusion of women in whom dissection was the first presentation of the underlying disease. ${ }^{13}$

Multiple factors impact the aorta during pregnancy. Increased haemodynamic stress and structural changes of the vascular wall may weaken the aortic wall in pregnant women with aortopathies. ${ }^{4-8}$ The increased risk for aortic complications persists in the postpartum period, but clear management guidelines for this period are lacking.

Current guidelines advocate the use of betablockers in women known with underlying aortic disease throughout pregnancy to prevent complications, but the evidence supporting this is weak and the effect on fetal growth needs further research. ${ }^{9}$ Atenolol has been associated with higher rates of fetal growth retardation. In contrast, metoprolol, labetalol, bisoprolol, propranolol and celiprolol in case of vEDS may be used safely during pregnancy, although caution with regard to fetal growth remains warranted. ${ }^{9}$

Use of large prospective datasets can help in addressing these specific issues and in determining the impact of pregnancy in women with aortic disease. In 2007, the Registry Of Pregnancy And Cardiac disease (ROPAC) was established by the EURObservational Research Programme (EORP) of the European Society of Cardiology (ESC) in order to provide contemporary information on the impact of pregnancy on a wide range of cardiovascular diseases. With this ancillary analysis, we aim to study the pregnancy outcome of women with thoracic aortic disease.

\section{METHODS}

The rationale and design of the ROPAC have been described previously. ${ }^{10}$ In brief, the registry started in January 2007. Women with structural heart disease from 60 hospitals in 28 countries (both developed and developing countries) were enrolled. It collected the following data relating directly to the pregnancy: age at conception, cardiovascular complications, obstetric complications, fetal complications, medication use, pregnancy duration and mode of delivery. 
In this substudy, we focus on patients with aortic disease including (1) women with known heritable thoracic aortic disease (HTAD) in particular MFS, vEDS or TS or with BAV (not associated with one of the former conditions) with and without aortic dilatation/dissection and (2) women without one of the prespecified HTAD or BAV, but with aortic dilatation or previous aortic dissection, grouped under the term 'Thoracic Aortic Dilatation/Dissection-TAD'. Because no specification of the exact location of aortic dilatation was requested in the questionnaires, we used the term ascending aorta throughout the paper referring to the ascending part of the thoracic aorta comprising both the root and tubular ascending aorta. No cutoff values for aortic dilatation were given in the questionnaires where the indication of aortic dilatation was left to the discretion of the including physician.

The following endpoints were studied: death; cardiovascular events: aortic dissection (type A and B), need for aortic surgery or intervention; obstetric complications: pregnancy-induced hypertension, (emergent) caesarean section (CS), premature birth and small for gestational age.

Details on ethical approval have been described previously. ${ }^{10}$

\section{Statistical analysis}

. Data are presented as mean values and SD if normally distributed and as median with IQR if skewed. Categorical data are presented as count divided by the total number of valid/available data. Differences in variables between diagnostic groups were evaluated by Student's t-test, Mann-Whitney U test, analysis of variance, Kruskal-Wallis test and $\chi^{2}$ test where appropriate. Data analyses were performed with SPSS V.27.0. A p value of $<0.05$ (two-sided test) was considered significant. Complete-case analysis was performed.

\section{Patient and public involvement}

Patients were not involved in the design, conduct, reporting or dissemination plans of our research.

\section{RESULTS}

\section{Baseline characteristics}

Thoracic aortic disease was reported in 189 out of 5739 women $(3.3 \%)$ included in the registry from 2007 until 2018. More than half of these were patients with MFS followed by patients with BAV. Prior to pregnancy, ascending aortic dilatation was documented in 81 patients, in 49 cases no data were available (tables 1 and 2). Eleven patients had a history of aortic dissection-10 type A dissections (5 patients with MFS and 5 patients with TAD of which 2 had a traumatic dissection) and 1 type $\mathrm{B}$ dissection in a patient with vEDS. Data on the extent of the dissection and type of surgery was not available. One patient with vEDS underwent stenting for a ruptured superior femoral artery 1 year before pregnancy. Seventeen women underwent a valvular intervention prior to pregnancy of which seven had a mechanical valve (one mitral and six aortic valves (one Bentall)). In five patients, prior valve sparing ascending aortic replacement was indicated in the questionnaire.

Data on left ventricular function were reported in 119 cases of which $3(2.5 \%)$ had a decreased ejection fraction prior to pregnancy. Two of these had a mildly impaired ejection fraction of $49 \%$ and $50 \%$, respectively (one patient with MFS and one patient with TAD) and one patient with MFS had a moderate reduced ejection fraction of $35 \%$ treated with furosemide and a beta-blocking agent preconception.

Forty-nine per cent (20/41) and 51\% (21/41) of the women with MFS known to have aortic dilatation were treated with a beta-blocking agent preconception and during pregnancy, respectively. Two out of the four included patients with vEDS were on beta-blockers (but none on celiprolol). Five women

Table 1 Baseline characteristics (prior to pregnancy) for each diagnostic group

\begin{tabular}{|c|c|c|c|c|c|c|c|}
\hline $\begin{array}{l}\text { Diagnosis } \\
\text { Number included }\end{array}$ & $\begin{array}{l}\text { MFS } \\
\mathrm{N}=100\end{array}$ & $\begin{array}{l}\mathrm{BAV} \\
\mathrm{N}=49\end{array}$ & $\begin{array}{l}\mathrm{TS} \\
\mathrm{N}=16\end{array}$ & $\begin{array}{l}\text { vEDS } \\
\mathrm{N}=4\end{array}$ & $\begin{array}{l}\mathrm{TAD} \\
\mathrm{N}=20\end{array}$ & $\begin{array}{l}\text { Total } \\
\mathrm{N}=189\end{array}$ & $P$ value \\
\hline Age (median (IQR)) & $29.1(25.4-32.8)$ & $31.1(25.4-34.3)$ & $30.2(27.6-34.3)$ & 28 & $31.1(28.5-36.5)$ & $31.5(29-36.9)$ & 0.17 \\
\hline Nulliparity & $57 / 100(57 \%)$ & $18 / 48(38 \%)$ & $10 / 16(63 \%)$ & $2 / 4(50 \%)$ & $12 / 20(60 \%)$ & $99 / 188(53 \%)$ & 0.18 \\
\hline Arterial hypertension & $12 / 97(12 \%)$ & $3 / 48(6 \%)$ & $4 / 16(25 \%)$ & $1 / 4(25 \%)$ & $4 / 19(21 \%)$ & $24 / 184(13 \%)$ & 0.33 \\
\hline $\begin{array}{l}\text { Smoking } \\
\text { (current-former) }\end{array}$ & $4-10 / 76$ & $1-6 / 36$ & $0-3 / 15$ & $1-0 / 4$ & $0-0 / 13$ & $6-19 / 144$ & 0.32 \\
\hline BMI (median (IQR)) & $22(20.4-24.7)$ & $25.3(21.9-30.7)$ & $27.3(24.3-30.8)$ & $22.4(20-29.4)$ & $24.5(22.2-26.5)$ & $24.5(22.2-26.5)$ & 0.01 \\
\hline Emerging country & $19 / 100(19 \%)$ & $18 / 49(37 \%)$ & $0 / 16$ & $0 / 4$ & $3 / 20(15 \%)$ & $40 / 189(21 \%)$ & 0.01 \\
\hline Aortic dilatation & $41 / 59(69 \%)$ & $24 / 42(57 \%)$ & $1 / 16(6 \%)$ & $0 / 3$ & $15 / 20(75 \%)$ & $81 / 140(58 \%)$ & $<0.001$ \\
\hline Dimension AA in mm (median (IQR)) & $40(35-45)$ & $42(40-44.3)$ & $42(42-42)$ & 1 & $41.5(39.3-46.8)$ & $42(38-45)$ & 0.68 \\
\hline Prior aortic dissection & $5 / 100(5 \%)$ & $0 / 42$ & $0 / 16$ & $1 / 4(25 \%)$ & $5 / 20(25 \%)$ & $11 / 182(6 \%)$ & $<0.001$ \\
\hline A & 5 & & & & 5 & $10 / 11$ & \\
\hline B & & & & 1 & & $1 / 11$ & \\
\hline BB & $4 / 5$ & & & $1 / 1$ & $2 / 2$ & & \\
\hline BAV & $4 / 96(4 \%)$ & 49 & $1 / 16(6 \%)$ & $0 / 4$ & 0 & $54 / 185(29 \%)$ & $<0.001$ \\
\hline Valvular intervention & $9 / 34(26 \%)$ & $6 / 17(35 \%)$ & $0 / 3$ & $0 / 1$ & $2 / 9(22 \%)$ & $17 / 64(27 \%)$ & 0.92 \\
\hline Aortic & $4(1 \mathrm{M}, 1 \mathrm{~B}, 2 ?)$ & $6(3 \mathrm{M}, 1 \mathrm{~B}, 2 \mathrm{R})$ & 1 & 1 & $2(2 \mathrm{M})$ & $12(6 \mathrm{M}, 2 \mathrm{~B}, 2 \mathrm{R}, 2 ?)$ & \\
\hline Mitral & $5(1 \mathrm{M}, 1 \mathrm{~B}, 3 ?)$ & 1 & 1 & 1 & 1 & $5(1 \mathrm{M}, 1 \mathrm{~B}, 3 ?)$ & \\
\hline \multicolumn{8}{|l|}{ Treatment } \\
\hline BB & $27 / 54(50 \%)$ & $5 / 18(28 \%)$ & $4 / 7(57 \%)$ & $2 / 2(100 \%)$ & $6 / 10(60 \%)$ & $44 / 91(48 \%)$ & 0.037 \\
\hline ACE-I & $1 / 49(0.02 \%)$ & $1 / 18(0.06 \%)$ & $0 / 7$ & $0 / 3$ & $1 / 13(0.08 \%)$ & $3 / 90(0.03 \%)$ & 0.34 \\
\hline ARB & $1 / 47(0.02 \%)$ & $0 / 18$ & $0 / 7$ & $0 / 2$ & $0 / 13$ & $1 / 87(0.01 \%)$ & 0.56 \\
\hline Diuretics & $1 / 49(0.02 \%)$ & $0 / 18$ & $0 / 7$ & $0 / 3$ & $0 / 13$ & $0 / 90$ & 0.93 \\
\hline VKA & $4 / 17(24 \%)$ & $4 / 8(50 \%)$ & $0 / 1$ & $0 / 0$ & $1 / 7(14 \%)$ & 9/33 (15\%) & 0.59 \\
\hline
\end{tabular}

Categorical variables are presented as count divided by the total number of valid/available data and percentages between brackets.

?, unknown; $A A$, ascending aorta; $A C E-I, A C E$ inhibitor; $A R B$, angiotensin receptor blocking agent; B, bioprosthesis; BAV, bicuspid aortic valve; $B B$, beta-blocking agent; IQR, interquartile range; $M$, mechanical valve; $M F S$, Marfan syndrome; $O A C$, oral anticoagulation; $R$, valve repair; TAD, thoracic aortic aneurysms and dissections; vEDS, vascular Ehlers-Danlos syndrome; VKA, vitamin K antagonist. 


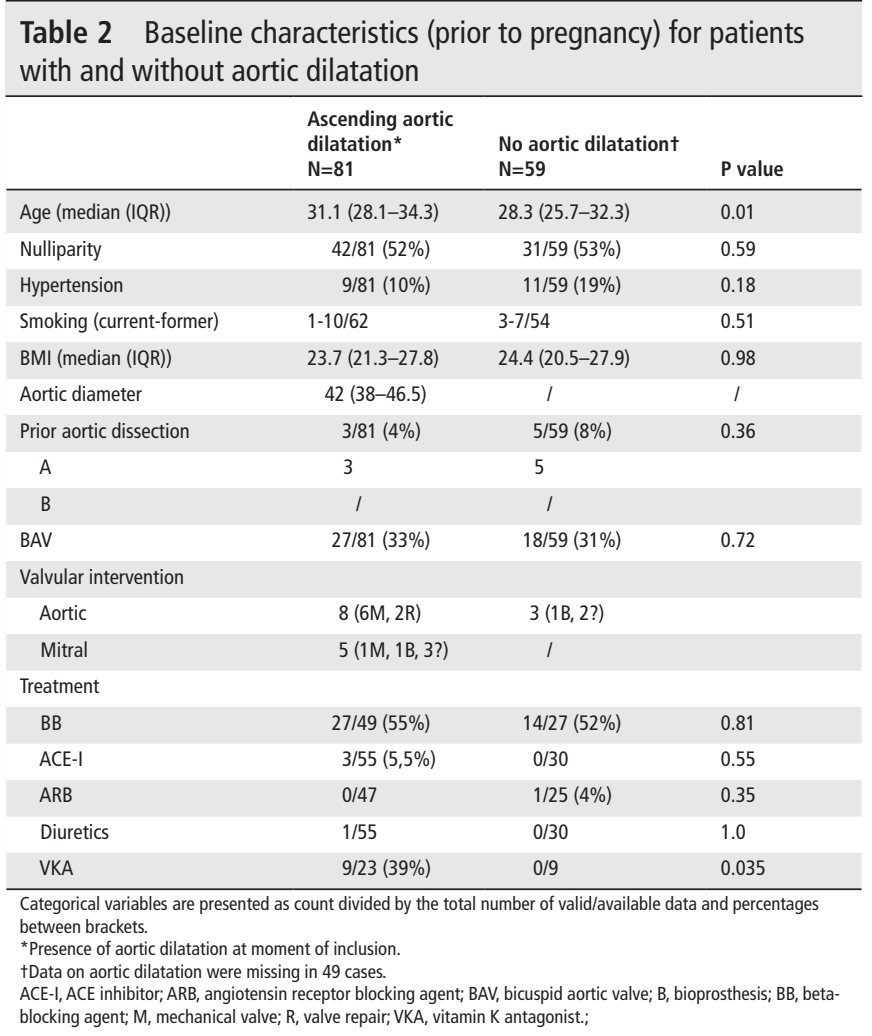

were on atenolol during pregnancy, the other women (of whom we have data) were treated with propranolol, labetalol, bisoprolol, celiprolol or metoprolol (56/91).

In total, nine women were treated with oral vitamin $\mathrm{K}$ antagonists, seven of which had a mechanical valve, the indication in two women was unknown. Demographic characteristics for each diagnostic group and for patients with or without aortic dilatation are described in tables 1 and 2, respectively.

\section{Cardiovascular complications}

Four patients (2\%) had an acute aortic dissection during pregnancy or in the postpartum period. Three were type A dissections requiring urgent surgical intervention and one type $B$ aortic dissection that was treated conservatively. There was no maternal mortality. The patient with the type B dissection had known MFS and was treated with beta-blockers before and throughout pregnancy. Her ascending aorta was moderately dilated up to $43 \mathrm{~mm}$ prior to pregnancy with a small insignificant increase of the diameter of $2 \mathrm{~mm}$ measured by echocardiography, descending thoracic aortic dimensions were not available. She presented with a type $\mathrm{B}$ aortic dissection in the third trimester. The three patients with type A dissections were not known with MFS or aortic dilatation prior to pregnancy and were thus not under medical attention. In two of them, the diagnosis of MFS was made following the acute event. One of them presented with dissection 1 week postpartum (aortic diameter not known) and the second one presented at 37 weeks of gestation, with an ascending aortic diameter of $55 \mathrm{~mm}$. The last patient experienced a type A aortic dissection at an ascending aortic diameter of $60 \mathrm{~mm}$ at 26 weeks of gestation. Data are summarised in table 3 .

\section{Obstetric and fetal outcome}

Overall, we observed a high CS rate of 63\% (86/137), but it was not performed more in women with aortic dilatation versus women with normal aortic dimensions $(p=0.37)$. Half $(29 / 58)$ of the patients with MFS underwent an elective CS and 16\% (9/58) urgent CS, (one patient with type A and one with type B aortic dissection, one due to aortic dilatation, five for obstetric reasons). All patients with vEDS (4/4) underwent an elective CS and 69\% (11/16) of the women with TS had a CS (7 elective and 4 urgent for non-cardiac reasons). All but one patient with previous aortic dissection had a CS of whom two urgent (one because of fetal distress and one for unknown reason).

No significant difference of pregnancy-induced hypertension or pre-eclampsia was noticed between the different disease groups (total of four women with pregnancy-induced hypertension and four with pre-eclampsia, $\mathrm{p}=0.68$ and $\mathrm{p}=0.85$, respectively).

There were no fetal deaths. The median gestational age was 38 weeks (37-39 weeks). Median birth weight was $2980 \mathrm{~g}$ (2660$3450 \mathrm{~g})$ and median birth weight centile ${ }^{11}$ 50th (22-77.5th). There was no significant difference in birth weight and in birth weight centile in women treated with a beta-blocking agent compared with untreated women (2960 g (2358-3390 g) vs $3270 \mathrm{~g}(2750-3570 \mathrm{~g})$, p value $=0.25$ and 46.5 th $(12.5-76$ th $)$ vs 44 th centile $(19.5-69$ th $)$, p value $=0.96)$. No significant differences were found in rates for intrauterine growth retardation or preterm birth.

\section{DISCUSSION}

The purpose of the ROPAC registry was to study maternal and fetal outcomes in pregnant women with structural and ischaemic heart disease, pulmonary arterial hypertension and aortic disease. It is the largest prospective dataset to date. Pregnancy outcomes collected over a 10-year period in 5739 pregnancies were recently published. ${ }^{12}$ Patients with aortic disease constituted a relatively small subgroup within this registry.

The spectrum of thoracic aortic disease included in ROPAC was broad. Half of the women included were patients with MFS who had the highest rate of cardiovascular complications during pregnancy and peripartum period. Despite this, the rate of aortic dissection was low (3/100) in those with MFS and no admissions for congestive heart failure were reported. All three aortic dissections in the patients with MFS occurred during the last trimester or shortly postpartum underscoring the risk for aortic dissection during the peripartum period. ${ }^{313} 14$ Only one of these three patients was known to have MFS prior to pregnancy. This

Table 3 Characteristics of patients presenting with aortic dissection during pregnancy

\begin{tabular}{lllll}
\hline & Pregnancy duration & Type of dissection & Diagnosis & Therapy during pregnancy (prior to \\
dissection)
\end{tabular}

?, unknown; $\mathrm{AA}$, ascending aorta; BB, beta-blocking agent; MFS, Marfan syndrome; pp, postpartum. 
supports previous data that the awareness for preconception diagnosis of MFS is not common in women with pregnancyassociated aortic dissection. ${ }^{1}$ Data from the GenTAC registry showed a high prevalence of pregnancy-related aortic dissections in MFS of up to $7.4 \%$, of which only $42 \%$ was aware of the diagnosis prior to pregnancy. ${ }^{3}$ Due to its retrospective design, it is assumable that there might have been an inclusion bias in the GenTAC registry. The same limitation may have played a role in ROPAC, although patients were prospectively included in the ROPAC registry three women were enrolled due to the occurrence of aortic dissection during index pregnancy.

Currently, there is no consensus at which dimension to recommend prophylactic aortic surgery preconception. European guidelines advise against pregnancy in patients with MFS with an aortic root diameter of $>45 \mathrm{~mm}$. Dissection rates below the threshold of $45 \mathrm{~mm}$ are low with prospective studies including patients with MFS with an aortic diameter $\leq 45 \mathrm{~mm}$ not reporting any cases of aortic dissections. ${ }^{14}$ A positive family history of dissection and rapid root growth $>3 \mathrm{~mm} / \mathrm{y}$ are however important risk factors to consider in the prepregnancy counselling. ${ }^{9}$

Unfortunately, even if preconception prophylactic aortic surgery is performed, this does not reduce the risk of vascular complications in other territories with a reported type B dissection rate in patients with MFS between 5.4\% and 10\% outside of pregnancy. ${ }^{15} 16$ This underscores the importance of imaging of the entire aorta prior to pregnancy in patients with MFS. ${ }^{9}$ Type B dissections might occur irrespective of aortic root dimensions. ${ }^{17} 18$ Data from a retrospective multicentre observational study reporting on pregnancy outcome in 151 patients with MFS with 258 pregnancies documented type B dissection in four patients $(1.6 \%)$ - one of these patients had previously undergone aortic root replacement. ${ }^{19}$

The next largest patient population in this registry were women with BAV. Fifty-seven per cent had aortic dilatation (24/42), but no aortic complications occurred. The reported dissection rate during pregnancy in BAV patients ranges from $0 \%$ to $4 \% .{ }^{20}$ In total, 16 women with TS were included. Unlike in MFS, much less is known about the risk of pregnancy-related aortic complications in TS. Underlying congenital and acquired cardiovascular anomalies including BAV, coarctation of the aorta or aortic dilation were present in the majority of published cases of aortic dissection. ${ }^{21}$ In the current analysis, none of the 16 women with TS experienced any cardiovascular event. Four had known preconception arterial hypertension and one had a BAV. Aortic dilatation was documented in one patient (with an ascending aorta diameter of $42 \mathrm{~mm}$-aortic size index $21.6 \mathrm{~mm} /$ $\mathrm{m}^{2}$ ).

Although last ESC guidelines contraindicated pregnancy in women with vEDS, four patients were enrolled, but no adverse events occurred. ${ }^{92}$ A retrospective analysis by Murray et al ${ }^{23}$ reported a pregnancy-related maternal mortality rate of $4.9 \%$ per delivery. The prevalence of arterial dissection/rupture and uterine rupture was $9.2 \%$ and $2.6 \%$, respectively.

Eleven per cent (20/189) of women were classified as 'TAD' because the underlying (genetic) diagnosis was not known. Post hoc, two of these TAD women were found to carry a pathogenic variant in a HTAD gene (one in SMAD3 and one in TGFBR2). It is possible that more of the women in the TAD group had an underlying genetic disorder explaining the presence of aortic dilatation/dissection in women of such a young age. Indeed, the presence of a pathogenic variant might predict a worse outcome, which is an important issue in the care for these patients with TAD. $^{24}$
It is widely accepted to treat pregnant patients with MFS with beta-blockers. The 2018 pregnancy guidelines advise that betablocking agents should be considered throughout pregnancy in women with MFS and other HTAD and indicate that it is the preferred therapy in the case of coexistent arterial hypertension. ${ }^{9}$ In ROPAC, only 51\% of pregnant women with MFS with aortic dilatation were treated with a beta-blocker. Birth weight tended to be lower when the mother had been treated with a beta-blocking agent, although this was not significant. Retrospective data from the UK demonstrate beta-blocker use in $64.2 \%$ of pregnant women with MFS with significant lower birth weight in patients on beta-blocking agents. ${ }^{19}$ Again, more prospective data are needed in order to draw definite conclusions.

There was a strikingly high rate of delivery by CS in this cohort (63\%). All patients with vEDS had an elective CS as recommended by the guidelines. Most Turner women also had a CS for unclear indications, most presumably related to small body size of the mother. There are limited data on the effect of labour, specifically the active phase of labour on the risk of aortic dissection. Although CS is considered an attractive option as it is scheduled and changes of maternal haemodynamics are less compared with labour, ${ }^{4}$ vaginal delivery is the preferred mode of delivery in the majority of patients with cardiovascular disease due to lower risk of infection, bleeding and morbidity postpartum. Data recently published by Minsart et a ${ }^{18}$ suggested that vaginal delivery with rigorous pain control and avoidance of the Valsalva manoeuvre might be safe in women with MFS and an aortic root diameter $\leq 45 \mathrm{~mm}$. However, further research addressing the mode and timing of delivery in TAD is necessary.

A dedicated ROPAC registry (ROPAC 3) for patients with aortic pathology has been initiated recently within the EORP with the aim of more accurately assessing the risks and outcomes during pregnancy. Some important issues, not yet included in ROPAC 1-2, are addressed such as data on aortic growth during pregnancy, dimensions of the distal aorta, details on genetic data and family history of aortic dissection.

\section{CONCLUSION}

The aortic dissection rate in women with thoracic aortic disease included in the ROPAC registry was low with good maternal and fetal outcomes. In three out of four women (75\%) with aortic dissection, this occurrence was the first presentation of the underlying disease. This highlights the importance of early recognition of the diagnosis and preconception counselling in order to achieve better pregnancy outcome. Type A dissections in patients with MFS occurred at diameters above the $45 \mathrm{~mm}$ guideline recommendation, suggesting a relatively safe margin. However, this does not exclude the risk for type B dissections. Complete aortic imaging prior to pregnancy in patients with MFS by CT scanning or MRI is therefore advised. In this registry, the use of beta-blockers was surprisingly low with no significant effect on birth weight, whereas CS rates were high despite lack of supporting data. If a woman after preconception counselling decides to pursue pregnancy despite the risks, close proximity to a tertiary care centre with experienced obstetricians, anaesthesiologists, cardiac surgeons and cardiologists with serial follow-up throughout pregnancy and the postpartum period with an individualised plan for delivery is advised.

\section{LIMITATIONS}

ROPAC only includes a small fraction of all the women with MFS or other aortopathy. On the one hand, it may be biased by the overrepresentation of an acute event allowing recognition 


\section{Key messages}

\section{What is already known on this subject?}

- Several retrospective data indicate a pregnancy-related risk for aortic dissection in women with aortopathy. However, these data are biased by the overrepresentation of an acute event allowing recognition of the aortopathy.

\section{What might this study add?}

- This ancillary analysis of the Registry Of Pregnancy And Cardiac disease registry provides the largest prospective data review on pregnancy risk for patients with a wide range of thoracic aortic disease who elect to pursue pregnancy. The overall complication rate was low with favourable maternal and fetal outcomes.

\section{How might this impact on clinical practice?}

- A multidisciplinary approach with serial follow-up in expert centres throughout pregnancy and the postpartum period with an individualised plan for delivery is advised in women with thoracic aortic disease.

of the aortopathy and on the other hand the sample is inherently biased towards aortopathy patients who may inherently be considered more safe for pregnancy.

No genetic or HTAD-specific phenotypic data or details on family history were available in the database. It is likely that the diagnosis of MFS was based on clinical manifestations in some cases. Patients with genetic TAD entities, overlapping with MFS such as LDS or Aneurysm Osteoarthritis Syndrome may have inadvertently been included in the MFS group.

A threshold diameter to define aortic dilatation was not specifically defined in the questionnaires, it was only filled in as 'dilatation yes/no' and dimensions were often not provided. The number of patients with aortic dilatation may therefore be underestimated. Nor was the exact location of aortic dilatation (root or tubular ascending aorta) prespecified in the questionnaires - we used the term 'ascending aorta' to keep uniformity throughout the paper.

Another limitation is that a registry relies on correct and complete completion of questionnaires by the enrolling centres, data on baseline characteristics are unfortunately missing in some cases. Also data on previous aortic interventions and complications that may have occurred were often not provided.

\section{Author affiliations}

'Department of Cardiology, Ghent University Hospital, Gent, Belgium

${ }^{2}$ Cardiology Department, Erasmus Medical Center, Rotterdam, Netherlands ${ }^{3}$ Division of Cardiology, Massachusetts General Hospital, Boston, Massachusetts, USA

${ }^{4}$ Adult Congenital Heart Disease Program. Knight Cardiovascular Institute, Oregon Health \& Sciences University, Portland, Oregon, USA

${ }^{5}$ Department of Cardiology, CUB Hôpital Erasme, Université Libre de Bruxelles, Bruxelles, Brussels, Belgium

${ }^{6}$ Department of Cardiology, CRMR Syndrome de Marfan et Apparentés, BichatClaude Bernard Hospital, Université de Paris, INSERM U1148, Paris, France

${ }^{7}$ Division of Cardiology, University of British Columbia, Pacific Adult Congenital Heart Disease Clinic, St Paul's Hospital, Vancouver, British Columbia, Canada

${ }^{8}$ Department of Metabolism, Digestion and Reproduction, Imperial College London, Chelsea and Westminster Hospital, London, UK

${ }^{9}$ Department of Cardiology, University of East Anglia, Faculty of Medicine, Norwich Research Park, Norwich, UK

${ }^{10}$ Center for Medical Genetics, Ghent University Hospital, Ghent, Belgium
Acknowledgements EORP oversight Committee, ROPAC Executive Committee (see online supplemental appendix 1). Data collection was conducted by the EORP department from the ESC by Elin Folkesson Lefrancq as Project Officer; Viviane Missiamenou, Gérard Gracia and Sebastien Authier as Data Managers. Overall activities were coordinated and supervised by Dr Aldo P Maggioni (Scientific Coordinator). Data have been presented at the congress of the European Society of Cardiology 2019. Julie De Backer is funded as a senior clinical researcher by the Research Foundation Flanders and by a Grant for Medical Research from the Baillet Latour Funds.

Collaborators The ROPAC investigators group: ARGENTINA—Buenos Aires: A Aquieri, A Saad, H Ruda Vega, J Hojman, J M Caparros, M Vazquez Blanco; AUSTRALIA—Elizabeth Vale: M Arstall, C M Chung, G Mahadavan, E Aldridge, M Wittwer, Y Y Chow, Herston: W A Parsonage, K Lust, New Lambton Heights: N Collins, G Warner, R Hatton, A Gordon, E Nyman; AUSTRIA—Innsbruck: J Stein, E Donhauser, Vienna: H Gabriel; AZERBAIJAN—Baku: A Bahshaliyev, F Guliyev, I Hasanova, T Jahangirov, Z Gasimov; BANGLADESH_Dhaka: A Salim, C M Ahmed, F Begum, M H Hoque, M Mahmood, M N Islam, P P Haque, S K Banerjee, T Parveen; BELGIUM—Brussels: M Morissens, Gent: J De Backer, L Demulier, M de Hosson, Leuven:W Budts, M Beckx; BOSNIA AND HERZEGOVINA—Banja Luka: M Kozic, M Lovric, T Kovacevic-Preradovic; BULGARIA—Sofia: N Chilingirova, P Kratunkov; CANADA—Edmonton: N Wahab, S McLean, Hamilton, Ontario: E Gordon, L Walter, Montreal: A Marelli, A R Montesclaros; COLOMBIA—Medellin: G Monsalve, C Rodriguez, F Balthazar, V Quintero, W Palacio, L A Mejía Cadavid, E Munoz Ortiz, F Fortich Hoyos, E Arevalo Guerrero, J Gandara Ricardo, J Velasquez Penagos; CZECH REPUBLIC — Hradec Kralove: Z Vavera, Prague: J Popelova; DENMARKCopenhagen: N Vejlstrup, L Grønbeck, M Johansen, A Ersboll; EGYPT—Alexandria: Y Elrakshy, Assiut: K Eltamawy, M Gamal Abd-El Aziz, Benha: A El Nagar, H Ebaid, H Abo Elenin, M Saed, S Farag, W Makled, Cairo: K Sorour, Z Ashour, G El-Sayed, M Abdel Meguid Mahdy, Minia: N Taha, A Dardeer, M Shabaan, Zagazig: A Saad, M Ali; FRANCE—Nice: P Moceri, Paris: G Duthoit, M Gouton, J Nizard, L Baris, S Cohen, M Ladouceur, D Khimoud, B lung; GERMANY —Berlin: F Berger, A Olsson, Bonn: U Gembruch, W M Merz, E Reinert, S Clade, Y Kliesch, Essen: C Wald, Hamburg: C Sinning, R Kozlik-Feldmann, S Blankenberg, E Zengin-Sahm, G Mueller, M Hillebrand, P Hauck, Y von Kodolitsch, N Zarniko, Muenster: H Baumgartner, R Schmidt, A Hellige, Munich: O Tutarel, H Kaemmerer, B Kuschel, N Nagdyman, Oldenburg: R Motz; GEORGIA—Tbilisi: D Maisuradze; GREECE—Athens: A Frogoudaki, E Iliodromitis, M Anastasiou-Nana, Marousi, D Triantafyllis, G Bekiaris, Thessaloniki: H Karvounis, G Giannakoulas, D Ntiloudi, S A Mouratoglou; HUNGARY_Budapest: A Temesvari, H Balint, D Kohalmi, B Merkely, C Liptai, Szeged: A Nemes, T Forster, A Kalapos, K Berek, K Havasi, N Ambrus; INDIA—Karad: A Shelke, R Kawade, S Patil; INDONESIA—Bandung: E Martanto, T M Aprami, A Purnomowati, C J Cool, M Hasan, R Akbar, S Hidayat, T I Dewi, W Permadi, D A Soedarsono IRAN - Tehran: M M AnsariRamandi, N Samiei, A Tabib, F Kashfi, S Ansari-Ramandi, S Rezaei IRAQ - Baghdad: H Ali Farhan, A Al-Hussein, G Al-Saedi, G Mahmood, I F Yaseen, L Al-Yousuf, M AlBayati, S Mahmood, S Raheem, T AlHaidari, Z Dakhil; IRELAND—Dublin: P Thornton, J Donnelly, M Bowen; ISRAEL—Beer Yakov: A Blatt, G Elbaz-Greener, Hadera: A Shotan, Haifa: S Yalonetsky, Rehovot: S Goland, M Biener; ITALY—Bologna: G Egidy Assenza, M Bonvicini, A Donti, A Bulgarelli, D Prandstraller, Bolzano: C Romeo, R Crepaz, Brescia: E Sciatti, M Metra, R Orabona, Massa: L Ait Ali, P Festa, Milan: V Fesslova, C Bonanomi, M Calcagnino, F Lombardi, A M Colli, M W Ossola, C Gobbi, E Gherbesi, L Tondi, M Schiavone, M Squillace, Palermo: M G Carmina, Torino: A Maina, C Macchi, E Gollo, F M Comoglio, N Montali, P Re, R Bordese, T Todros, V Donvito, W Grosso Marra, Trieste: G Sinagra, B D'Agata Mottolese, M Bobbo, V Gesuete, S Rakar, F Ramani; JAPAN—Chiba: K Niwa; KAZAKHSTAN—Almaty: D Mekebekova, A Mussagaliyeva, T Lee; KYRGYZSTAN—Bishkek: E Mirrakhimov, S Abilova, E Bektasheva, K Neronova, O Lunegova; LITHUANIA—Kaunas: R Žaliūnas, R Jonkaitiené, J Petrauskaité, Vilnius: A Laucevicius, D Jancauskaite, L Lauciuviene, L Gumbiene, L Lankutiene, S Glaveckaite, M Laukyte, S Solovjova, V Rudiene; MALAYSIA—Kuala Lumpur: KH Chee, C C-W Yim, H L Ang, R Kuppusamy, T Watson MALTA - Birkirkara: M Caruana; NORWAY — Oslo: M-E Estensen; PAKISTAN— Rawalpindi: M G A Mahmood Kayani, R Munir; POLAND—Bialystok: A TomaszukKazberuk, B Sobkowicz, J Przepiesc, Krakow: A Lesniak-Sobelga, L Tomkiewicz- Pajak, M Komar, M Olszowska, P Podolec, S Wisniowska-Smialek, Lodz: M Lelonek, U Faflik, A Cichocka-Radwan, Poznan: K Plaskota, O Trojnarska; PORTUGALCoimbra: N Guerra, Lisboa: L de Sousa, Porto: C Cruz, V Ribeiro; REPUBLIC OF MACEDONIA—Skopje: S Jovanova; ROMANIA—Bucharest: V Petrescu, R Jurcut, C Ginghina, I Mircea Coman, M Musteata; RUSSIA-Belgorod: 0 Osipova, T Golivets, I Khamnagadaev, 0 Golovchenko, A Nagibina, I Ropatko, Izhevsk: I R Gaisin, L Valeryevna Shilina, Moscow: N Sharashkina, Saint- Petersburg: E Shlyakhto, 0 Irtyuga, O Moiseeva, E Karelkina, I Zazerskaya, A Kozlenok, I Sukhova; SERBIA- 
Belgrade: L Jovovic; SLOVENIA—Ljubljana: K Prokšelj, M Koželj; SOMALILAND— Hargeisa: A 0 Askar, A A Abdilaahi, M H Mohamed, A M Dirir; SOUTH AFRICA—Cape Town: K Sliwa, Houghton: P Manga; SPAIN—Barcelona: A Pijuan-Domenech, L Galian-Gay, P Tornos, M T Subirana, M T Subirana, Bilbao: N Murga, Madrid: J M Oliver, B Garcia-Aranda Dominguez, I Hernandez Gonzalez, J F Delgado Jimenez, P. Escribano Subias; SUDAN—Khartoum: A Elbushi, A Suliman, K Jazzar, M. Murtada, N. Ahamed; SWEDEN—Göteborg: M Dellborg, E Furenas, M Jinesjo, K Skoglund, P Eriksson, T Gilljam, Lund: U Thilen; SWITZERLAND—Basel: D Tobler, Bern: K Wustmann, F Schwitz, M Schwerzmann, Lausanne: T Rutz, J Bouchardy, Zurich: M Greutmann, B M Santos Lopes, L Meier, M Arrigo; THE NETHERLANDS—Amsterdam: K de Boer, T Konings, Enschede: E Wajon, L J Wagenaar, Geldrop: P Polak, Groningen: E P G Pieper, Rotterdam: J Roos-Hesselink, L Baris, I van Hagen, H Duvekot, J M J Cornette, The Hague: C De Groot, Utrecht: C van Oppen; TURKEY_-Istanbul: L Sarac, O Batukan Esen, S Catirli Enar; UGANDA—Kampala: C Mondo, P Ingabire, B Nalwanga, T Semu; UNITED ARAB EMIRATES—Abu Dhabi: B T Salih, W A R Almahmeed, S Wani, F S Mohamed Farook, Al Ain, F Gerges, A M Komaranchath, F Al bakshi, Dubai: A Al Mulla, A H Yusufali, E I Al Hatou, N Bazargani, F Hussain; UK-Birmingham: L Hudsmith, P Thompson, S Thorne, S Bowater, Buckinghamshire: A Money-Kyrle, P Clifford, P Ramrakha, S Firoozan, J Chaplin, N Bowers, Coventry: D Adamson, London: F Schroeder, R Wendler, S Hammond, P Nihoyannopoulos, Norwich Norfolk: R Hall, L Freeman, Southampton: G Veldtman, J Kerr, L Tellett; USA—Boston: N Scott, A B Bhatt, D DeFaria Yeh, M A Youniss, M Wood, A A Sarma, S Tsiaras, A Stefanescu, J M Duran, L Stone, Cleveland: D S Majdalany, J Chapa, Detroit: K Chintala, P Gupta, Hershey, PA: J Botti, J Ting, W R Davidson, Lexington, Kentucky: G Wells, D Sparks, Mineola, New York: V Paruchuri, K Marzo, D Patel, Minneapolis: W Wagner, S N Ahanya, L Colicchia, T Jentink, K Han, M Loichinger, M Parker, W Wagner, C Longtin, Omaha: A Yetman, K Erickson, J Cramer, S Tsai, B Fletcher, S Warta, Phoenix: C Cohen, C Lindblade, R Puntel, K Nagaran, N Croft, Seattle: M Gurvitz, C Otto, Stanford, California: C Talluto, D Murphy, M G Perlroth.

Contributors JWR-H, JDB and LC conceived the idea for this study. LC and LB conducted the data analyses. The initial draft of the manuscript was produced by LC. LC, JDB, LB and JWR-H were involved in interpreting the results and writing the manuscript. LC and LB act as guarantors. All authors contributed to revising the manuscript critically for important intellectual content and approved the final version of the manuscript.

Funding Funding from 'Zabawas Foundation' and 'De Hoop Foundation' in addition to the support from EORP is greatly acknowledged. Since the start of EORP, the following companies have supported the programme: Abbott Vascular Int. (2011-2021), Amgen Cardiovascular (2009-2018), AstraZeneca (2014-2021), Bayer AG (2009-2018), Boehringer Ingelheim (2009-2019), Boston Scientific (2009-2012), The Bristol Myers Squibb and Pfizer Alliance (2011-2019), Daiichi Sankyo Europe GmbH (2011-2020), The Alliance Daiichi Sankyo Europe GmbH and Eli Lilly and Company (2014-2017), Edwards (2016-2019), Gedeon Richter PIc. (2014-2016), Menarini Int. Op. (2009-2012), MSD-Merck \& Co. (2011-2014), Novartis Pharma AG (2014-2020), ResMed (2014-2016), Sanofi (2009-2011), SERVIER (2009-2021), Vifor (2019-2022).

\section{Competing interests None declared.}

Patient consent for publication Not required.

Provenance and peer review Not commissioned; externally peer reviewed.

Data availability statement All data relevant to the study are included in the article or uploaded as supplementary information.

Author note The Erasmus MC, Bichat-Claude Bernard Hospital and Gent University Hospital are members of the European Reference Network for Rare Multisystemic Vascular Disease (VASCERN). Project ID: 769036.

Supplemental material This content has been supplied by the author(s). It has not been vetted by BMJ Publishing Group Limited (BMJ) and may not have been peer-reviewed. Any opinions or recommendations discussed are solely those of the author(s) and are not endorsed by BMJ. BMJ disclaims all liability and responsibility arising from any reliance placed on the content. Where the content includes any translated material, BMJ does not warrant the accuracy and reliability of the translations (including but not limited to local regulations, clinical guidelines, terminology, drug names and drug dosages), and is not responsible for any error and/or omissions arising from translation and adaptation or otherwise.

Open access This is an open access article distributed in accordance with the Creative Commons Attribution Non Commercial (CC BY-NC 4.0) license, which permits others to distribute, remix, adapt, build upon this work non-commercially, and license their derivative works on different terms, provided the original work is properly cited, appropriate credit is given, any changes made indicated, and the use is non-commercial. See: http://creativecommons.org/licenses/by-nc/4.0/.

\section{ORCID iDs}

Laurence Campens http://orcid.org/0000-0002-5045-2449

Jasmine Grewal http://orcid.org/0000-0001-7312-6278

Julie De Backer http://orcid.org/0000-0001-8878-1507

Jolien W Roos-Hesselink http://orcid.org/0000-0002-6770-3830

\section{REFERENCES}

1 van Hagen IM, Roos-Hesselink JW. Aorta pathology and pregnancy. Best Pract Res Clin Obstet Gynaecol 2014;28:537-50.

2 Pacini L, Digne F, Boumendil A, et al. Maternal complication of pregnancy in Marfan syndrome. Int I Cardiol 2009;136:156-61.

3 Roman MJ, Pugh NL, Hendershot TP. Aortic complications associated with pregnancy in Marfan syndrome: the NHLBI national Registry of genetically triggered thoracic aortic aneurysms and cardiovascular conditions (GenTAC).. Am Heart Assoc 2016;5.

4 Ouzounian JG, Elkayam U. Physiologic changes during normal pregnancy and delivery. Cardiol Clin 2012;30:317-29.

5 Nolte JE, Rutherford RB, Nawaz S, et al. Arterial dissections associated with pregnancy. J Vasc Surg 1995;21:515-20.

6 Renard M, Muiño-Mosquera L, Manalo EC, et al. Sex, pregnancy and aortic disease in Marfan syndrome. PLOS One 2017;12:e0181166.

7 Wanga S, Silversides C, Dore A, et al. Pregnancy and thoracic aortic disease: managing the risks. Can J Cardiol 2016;32:78-85.

8 Osol G, Ko NL, Mandalà M. Plasticity of the maternal vasculature during pregnancy. Annu Rev Physiol 2019;81:89-111.

9 Regitz-Zagrosek V, Roos-Hesselink JW, Bauersachs J, et al. 2018 ESC guidelines for the management of cardiovascular diseases during pregnancy. Eur Heart J 2018;39:3165-241.

10 Roos-Hesselink JW, Ruys TPE, Stein JI, et al. Outcome of pregnancy in patients with structural or ischaemic heart disease: results of a Registry of the European Society of cardiology. Eur Heart J 2013;34:657-65.

11 Nicolaides KH, Wright D, Syngelaki A, et al. Fetal medicine Foundation fetal and neonatal population weight charts. Ultrasound Obstet Gynecol 2018:52:44-51.

12 Roos-Hesselink J, Baris L, Johnson M. Pregnancy outcomes in women with cardiovascular disease: evolving trends over 10 years in the ESC registry of pregnancy and cardiac disease (ROPAC). Eur Heart J 2019

13 Sayama S, Takeda N, Iriyama T. Peripartum type B aortic dissection in patients with Marfan syndrome who underwent aortic root replacement: a case series study. BJOG 2017.

14 Kim SY, Wolfe DS, Taub CC. Cardiovascular outcomes of pregnancy in Marfan's syndrome patients: a literature review. Congenit Heart Dis 2018;13:203-9.

15 den Hartog AW, Franken R, Zwinderman AH, et al. The risk for type B aortic dissection in Marfan syndrome. J Am Coll Cardiol 2015;65:246-54.

16 Roman MJ, Devereux RB, Preiss LR, et al. Associations of age and sex with Marfan phenotype: the National Heart, Lung, and Blood Institute GenTAC (genetically triggered thoracic aortic aneurysms and cardiovascular conditions) registry. Circ Cardiovasc Genet 2017;10.

17 Mimoun L, Detaint D, Hamroun D, et al. Dissection in Marfan syndrome: the importance of the descending aorta. Eur Heart J 2011;32:443-9.

18 Minsart A-F, Mongeon F-P, Laberge A-M, et al. Obstetric and cardiac outcomes in women with Marfan syndrome and an aortic root diameter $\leq 45 \mathrm{~mm}$. Eur J Obstet Gynecol Reprod Biol 2018;230:68-72.

19 Cauldwell M, Steer PJ, Curtis SL, et al. Maternal and fetal outcomes in pregnancies complicated by Marfan syndrome. Heart 2019;105:1725-31.

20 Siu SC, Silversides CK. Bicuspid aortic valve disease. J Am Coll Cardiol 2010;55:2789-800.

21 De Backer J, Muiño Mosquera L, Demulier L. Aortopathy. In: Roos-Hesselink J, Johnson MR, eds. Springer International Publishing, 2017: 165-94.

22 European Society of Gynecology (ESG), Association for European Paediatric Cardiology (AEPC), German Society for Gender Medicine (DGesGM), et al. ESC guidelines on the management of cardiovascular diseases during pregnancy: the task force on the management of cardiovascular diseases during pregnancy of the European Society of cardiology (ESC). Eur Heart J 2011;32:3147-97.

23 Murray ML, Pepin M, Peterson S, et al. Pregnancy-related deaths and complications in women with vascular Ehlers-Danlos syndrome. Genet Med 2014;16:874-80.

24 Arnaud P, Hanna N, Benarroch L, et al. Genetic diversity and pathogenic variants as possible predictors of severity in a French sample of nonsyndromic heritable thoracic aortic aneurysms and dissections (nshTAAD). Genet Med 2019;21:2015-24. 